\title{
Antimicrobial Effects of Sulfadimethoxine on Salmonella, Escherichia coli and Aerobic plate count (APC) in Small-Scale Broiler Operations
}

\author{
Wannee Tangkham ${ }^{1} \&$ Frederick LeMieux ${ }^{1}$ \\ ${ }^{1}$ College of Agricultural Sciences, McNeese State University, Lake Charles, LA, United States \\ Correspondence: Wannee Tangkham, College of Agricultural Sciences, McNeese State University, United States. \\ E-mail: wtangkham@mcneese.edu
}

Received: September 7, 2019

doi:10.5539/jfr.v8n6p147
Accepted: October 4, 2019 Online Published: November 20, 2019

URL: https://doi.org/10.5539/jfr.v8n6p147

\begin{abstract}
Poultry is a source of Salmonella and Escherichia coli. Antibiotics can be used to reduce the enumeration and prevalence of these bacteria. The objective of this study was to determine the effects of sulfadimethoxine antibiotic on the enumeration and prevalence of Salmonella, Escherichia coli and aerobic plate count in broilers. Broilers $(n=600)$ were allotted to two treatments, each with twelve replications. The treatments were control (drinking water without antibiotic) and with antibiotic at $0.05 \%(\mathrm{wt} / \mathrm{vol})$ sulfadimethoxine. After a six-week period, the enumeration of Salmonella in the experimental treatment was detected at $2.55 \log \mathrm{CFU} / \mathrm{g}$. This value is not different $(\mathrm{P}>0.05)$ than that detected in the control at $2.81 \log \mathrm{CFU} / \mathrm{g}$. With respect to prevalence, there was a difference $(\mathrm{P}<0.05)$ between the experimental treatment at $90.0 \%$ and the control at $100 \%$. The enumeration of $E$. coli in the experimental treatment was detected at $3.97 \log \mathrm{CFU} / \mathrm{g}$. This value is lower $(\mathrm{P}<0.05)$ than that detected in the control treatment at $4.37 \log \mathrm{CFU} / \mathrm{g}$. With respect to prevalence, there was no difference $(\mathrm{P}>0.05)$ between the experimental treatment at $100 \%$ and the control at $100 \%$. The enumeration of aerobic plate count in the antibiotic treatment were detected at $6.62 \mathrm{log} \mathrm{CFU} / \mathrm{g}$. This value is lower $(\mathrm{P}<0.05)$ than that detected in the control at $7.50 \log \mathrm{CFU} / \mathrm{g}$. With respect to prevalence, there was no difference $(\mathrm{P}>0.05)$ between treatments. Our overall findings suggest that the use of the antibiotic sulfadimethoxine can reduce the number of E. coli, Salmonella and aerobic plate count in the small-scale broiler operations.
\end{abstract}

Keyword: sulfadimethoxine, Salmonella, E. coli, aerobic plate count, small-scale

\section{Introduction}

Poultry is a host for the bacteria Salmonella (Lee, Runyon, Herrman, Phillips, \& Hsieh, 2015) and Escherichia coli (Nolan, 2019) which can be a source of human illness (Haleem, Al-bakri, \& Al-Hiyaly, 2013). Increased attention has been given to reducing the level of these bacteria in pre- and post-harvest poultry with the aim to reduce the level and incidence of raw product contamination.

Antimicrobial therapy is an important tool in reducing microorganisms in poultry production (Aarestrup, 2015) and enhances growth productivity (Page \& Gautier, 2012). However, the use of antibiotics in animal production may produce resistant bacteria which could limit the effectiveness of antibiotics in humans (Simonsen et al., 1998; Klare et al., 1999; Van, London, Driessen, \& Stobberingh, 2001). Salmonellosis is one of the most common foodborne diseases caused by Salmonella in poultry and can transmitted to humans (Authority, 2016; Antunes, Mourão, Campos, \& Peixe, 2016). Colibacillosis is an infectious disease caused by $E$. coli which may produce morbidity and mortality in poultry (Piercy \& West, 1976; DeRosa, Ficken, \& Barnes, 1992; Lutful, 2010). Aerobic plate count (APC) is commonly used to assess the microbial load of poultry and the counts can be used to determine the quality, safety and shelf life of poultry products (Haleem et al., 2013; Rouger, Tresse, \& Zagorec, 2017). Growth of spoilage bacteria lead to defects in meat products and can be responsible for unwanted taste, color, odor, and texture. An APC count at $7 \mathrm{log} \mathrm{CFU} / \mathrm{g}$ or greater is used to define food spoilage (Zhang et al., 2012; Höll, Behr, \& Vogel, 2016) which is associated with food-borne illness (Rouger et al., 2017). Therefore, there is a need to find an alternative antibiotic for prevention of Salmonella and E. coli infections and reducing the number of APC in poultry production.

Sulfonamide is commonly used to treat upper respiratory (Delaplane, 1945), coccidial infections caused by 
Eimeria tenella and Eimeria necatrix (Waletzky \& Hughes, 1946; Grumbles \& Delaplane, 1948) and promote growth in poultry (Whitehill, Oleson, \& Hutchings, 1950; Aarestrup, 2000). The commonly used sulfonamide in poultry production is sulfadimethoxine and therefore is appropriate for in vivo testing (FDA, 2013). Sulfadimethoxine can be used to treat coccodiosis (Orton \& Hambly, 1971), fowl cholera, and coryza in poultry (Vree \& Hekster, 1987; Wang, MacNeil, \& Kay, 2012). In addition, sulfadimethoxine improves weight gain and final body weight (Davami, Peterson, Jones, \& Ilardi,1987). Previous studies showed that sulfadimethoxine can reduce the number of Campylobacter spp. and C. jejuni in growing broilers (Tangkham, Janes, \& LeMieux, 2016a) and turkeys (Alexandra, 2009). Therefore, most previous studies have concentrated on the transmission routes from commercial flock farm to carcasses after slaughter and retail products with limited information on the effects of production practices within small-scale poultry operations. The purpose of this study is to use antimicrobial therapy techniques to control bacterial contamination in poultry. Specifically, this study examines the effects of sulfadimethoxine antibiotic on the enumeration of Salmonella, E. coli and aerobic plate count in growing broilers.

\section{Method}

\subsection{Broiler Production}

The research experiment was approved by the McNeese State University Institutional Animal Care and Use Committee prior to data collection. Broilers were obtained from the McNeese State University Research Farm in Lake Charles, Louisiana. Birds ( $\mathrm{n}=600$ Ross $\mathrm{x}$ Ross) were allotted to one of two treatments: 1) control (drinking water without antibiotic) and 2) drinking water $+0.05 \%(\mathrm{wt} / \mathrm{vol})$ sulfadimethoxine (Durvet Inc., Blue Springs, Missouri). Drinking water was refreshed every day in both treatment groups. Feces was collected to determine Salmonella, Escherichia coli and aerobic plate counts from January 2014 to May 2014. Birds were housed in a controlled environment and maintained in Petersime ${ }^{\circledR}$ Battery Cages $\left(32^{\circ} \mathrm{C}\right)$ with raised wire flooring (Petersime Incubator Co., Gettysburg, OH). Each cage was divided into 12 pens of equal size of $74.7 \mathrm{~cm} \times 99.1$ $\mathrm{cm} \times 24.13 \mathrm{~cm}$ (Tangkham et al., 2016a; Tangkham, Janes, LeMieux, 2016b). Each pen housed twenty-five birds. Individual water and feed troughs were provided for each pen and supplied ad libitum. Birds were provided a commercial $18 \%$ protein chick grower crumbles with no antibiotics. The housing system was emptied of birds, feed, and litter and cleaned with hot water wash and disinfected. Animal care givers monitored feed and water and removed litter trays daily. Normal pest and rodent control were maintained throughout the experiment. The temperature and $\% \mathrm{RH}$ during time period was $32^{\circ} \mathrm{C}$ and $58 \%$, respectively.

\subsection{Bacterial Isolation and Identification}

The microorganisms were determined following the standards of the Association of Official Analytical Chemists (AOAC, 2000). Each week, fecal samples via swabbing were randomly collected from individual broilers $(\mathrm{n}=$ 600). To determine the enumeration (log CFU/g) and prevalence (\%) of E. coli and Salmonella, samples were plated on brilliant green agar. For aerobic plate count, samples were plated on nutrient agar.

Samples were plated on $3 \mathrm{M}^{\mathrm{TM}}$ Petrifilm to determine the enumeration (log CFU/g) of E. coli and APC. Salmonella was isolated with brilliant green agar. Plates were incubated in a horizontal position, clear side up in stacks of no more than 20 plates at $37^{\circ} \mathrm{C}$ for $24-48 \mathrm{~h}$. Results were obtained by selecting a countable plate (30-300 colonies) and the colonies were counted and reported as CFU/g.

\subsection{Statistical Analysis}

Statistical analysis was performed using SAS windows (SAS, 2003). The Proc GLM procedures were used to evaluate the significance differences of the obtained data. The PDIFF option of LSMEANS was employed to determine significance $(\mathrm{P}<0.05)$ among treatments. All data are presented as means with standard deviation $(\mathrm{SD})$ and a significance level of was used for statistical analysis of means from treatments.

\section{Results and Discussion}

\subsection{Enumeration of Salmonella}

Feces was collected and plated to determine the enumeration of Salmonella. The enumeration of Salmonella ranged from 0-4.25 log CFU/g. Salmonella increased from week 1 through week 3 in both the control and antibiotic treatments (Figure 1). Specifically, the counts of Salmonella in the control treatment increased from an initial value of $1.22 \mathrm{log}$ CFU/g in week one to a maximum value of $4.25 \mathrm{log}$ CFU/g in week three (Figure 1). In the antibiotic treatment, the initial value was not detected in week one but increased to $4.02 \mathrm{log} \mathrm{CFU} / \mathrm{g}$ in week three (Figure 1). Our study supported previous studies that poultry is a source of Salmonella, which leads to contamination of diverse foodstuffs (Barrow, Jones, Smith, \& Wigley, 2012; Mazengia et al., 2014; Crump, Sjolund, Gordon, \& Parry, 2015; Cosby et al., 2015). 
For the overall experiment, there was no difference $(\mathrm{P}>0.05)$ in the enumeration of Salmonella in the antibiotic treatment and the control treatment in weeks 1 through 6. However, the counts of Salmonella in the antibiotic treatment of $2.55 \mathrm{log} \mathrm{CFU} / \mathrm{g}$ was lower than in the control treatment at $2.81 \mathrm{log}$ CFU/g. Similar, to previous studies (Seiffert, Hilty, Perreten, \& Endimiani, 2013; Mazengia et al., 2014; Aarestrup, 2015) which indicated that the use of antibiotics had significantly lower rates of recovery of Salmonella. These results suggest that the antibiotic sulfadimethoxine, as applied in this study reduces the enumeration of Salmonella in small-scale poultry farming.

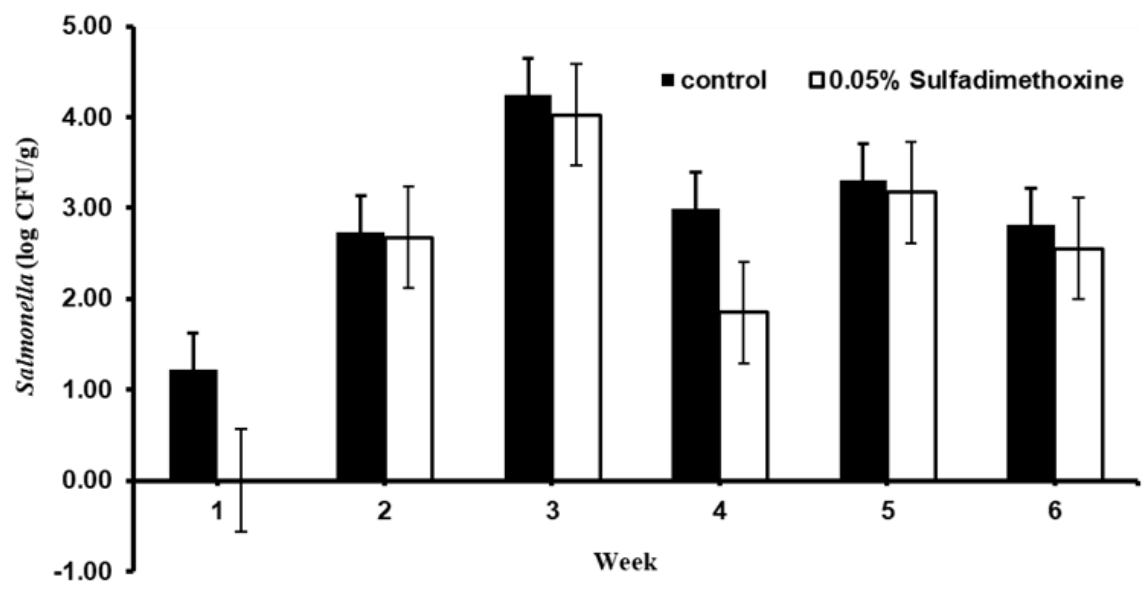

Figure 1. Salmonella counts in live broilers from the control and antibiotic treatments from weeks 1 through 6 Data are means from two replications. SEM=3.590

\subsection{Enumeration of E. coli}

The number of $E$. coli ranged from 3.67-4.55 log CFU/g. There was a small decrease in the enumeration of $E$. coli in the control treatment in weeks 1 through 6 from $4.39 \log$ CFU/g to $4.37 \log$ CFU/g. At week 6, the counts of $E$. coli decreased in the antibiotic treatment from $4.35 \mathrm{log}$ CFU/g to $3.97 \log$ CFU/g (Figure 2). These results were similar to the previous study (Tessi, Salsi, Caffer, \& Moguilevsky, 1997) which found that the use of sulfamethoxazole-trimethoprim as an antibiotic can inhibit the growth of E. coli. Other studies by Huff, Huff, Rath, Balog, \& Donoghue (2002) used a bacteriophage aerosol spray as an antibiotic to reduce the mortality rate of $E$. coli and their results showed that there was a significant decrease in mortality when the birds were challenged with E. coli immediately after bacteriophage administration. Other researchers (Al-Ghamdi, El-Morsy, Al-Mustafa, Al-Ramadhan, \& Hanif, 1999) also found that ampicillin and tetracycline can be used to inhibit the growth of $E$. coli from chickens. For the overall experiment, the enumeration of $E$. coli in the antibiotic treatment was lower $(\mathrm{P}<0.05) 3.97 \log \mathrm{CFU} / \mathrm{g}$ than the control treatment at $4.37 \mathrm{log} \mathrm{CFU} / \mathrm{g}$. These results suggest that the antibiotic sulfadimethoxine, as applied in this study reduces the enumeration of $E$. coli in small-scale poultry farming.

\subsection{Enumeration of Aerobic Plate Count}

After a six-week period, the enumeration of aerobic plate count ranged 6.46-7.93 log CFU/g. These data were related to the previous study by Haleem et al. (2013) who tested the counts of microflora at $6.55 \mathrm{log} \mathrm{CFU} / \mathrm{g}$ in poultry meat. Our study showed that the counts of APC steadily increased from week 1 through week 6 in the control treatment from an initial value of $6.72 \mathrm{log}$ CFU/g to a maximum value of $7.5 \mathrm{log}$ CFU/g (Figure 3). This may be due to the elevated initial viable count of APC (Haleem et al., 2013) and microbial spoilage occurs because of the growth and metabolic activities of spoiling bacteria (Zhang, et al., 2012; Höll et al., 2016; Rouger et al., 2017). For the overall experiment, the enumeration of aerobic plate count in the antibiotic treatment was significantly lower (6.62 log CFU/g) than in the control treatment (7.50 log CFU/g). Therefore, our results found that the antibiotic sulfadimethoxine, as applied in this study reduces the enumeration of aerobic plate count in small-scale poultry farming. 


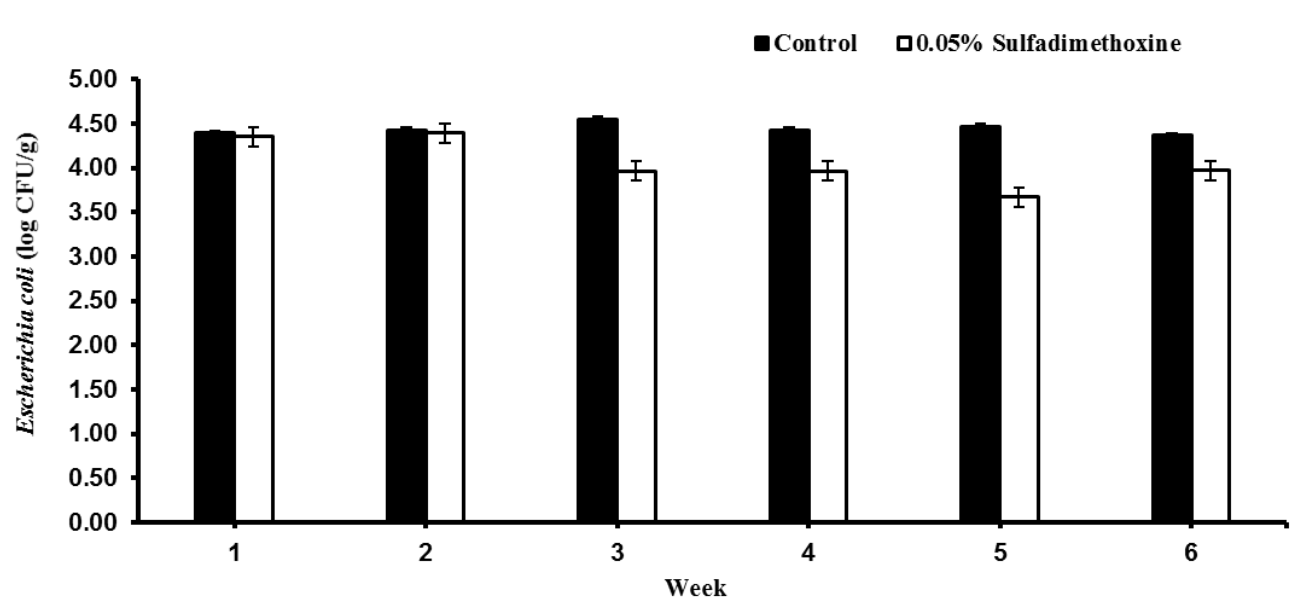

Figure 2. E. coli counts in live broilers from the control and antibiotic treatments from weeks 1 through 6 Data are means from two replications. SEM=3.410

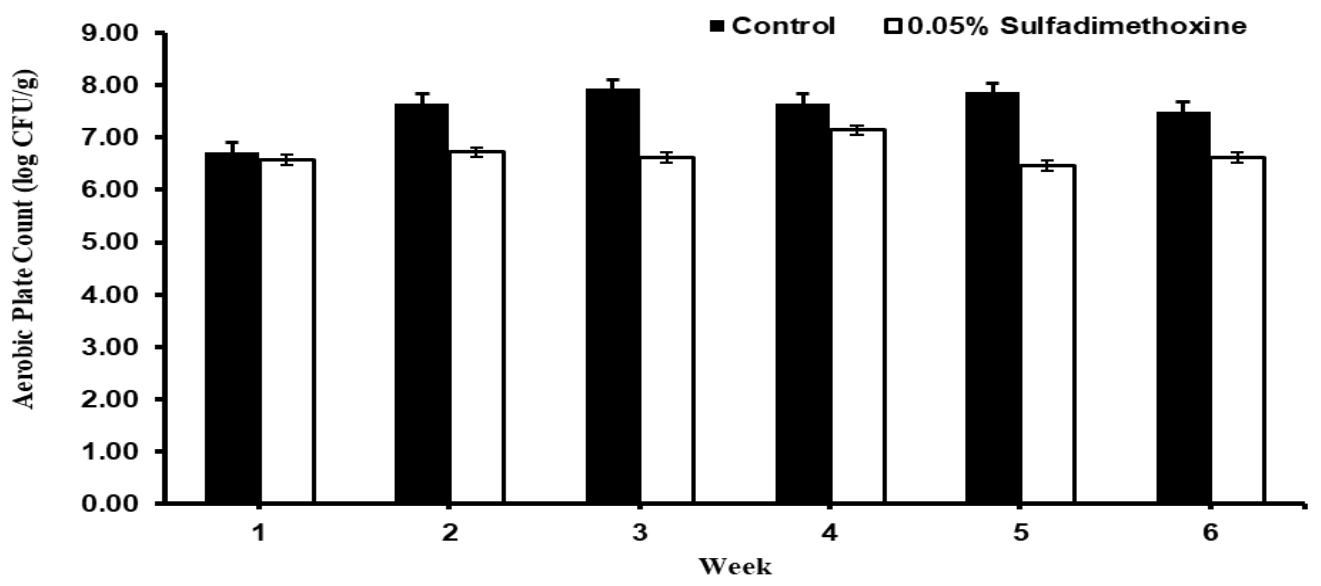

Figure 3. APC counts in live broilers from the control and antibiotic treatments from weeks 1 through 6

Data are means from two replications. SEM= 6.820

\subsection{Prevalence of Salmonella, E. coli and Aerobic Plate Count}

The prevalence of Salmonella, E. coli and aerobic plate counts were randomly tested from individual broilers (n $=300$ ) in both treatments. At week 1, the prevalence of aerobic plate count was detected from both treatments at $100 \%$. For Salmonella and E. coli were found at $96.7 \%$ in the control treatment (Table 1). In week 2, the prevalence of Salmonella, E. coli and aerobic plate count were detected $100 \%$ in both control and experimental treatments. In week 3, the prevalence of Salmonella, E. coli and aerobic plate count were declined in the control and the antibiotic treatment $(\mathrm{P}<0.05)$ (Table 1). Specifically, they were lower $(\mathrm{P}<0.05)$ in the antibiotic treatment at $83.3 \%, 76.7 \%$, and $93.3 \%$ of Salmonella, E. coli and aerobic plate count, respectively. These finding showed that the antibiotic sulfadimethoxine can reduce the prevalence of these microorganisms in broilers especially in week 3 (Table 1). Overall, for the six-week period of testing, the prevalence of Salmonella in the antibiotic treatment was lower $(\mathrm{P}<0.05)$ than in the control treatment (Table 1). Similar, to the studies of Hanson, Kaneene, Paduangtod, Hirokawa, \& Zeno (2002) who concluded that tetracycline, nalidixic acid, florfenicol, ampicillin, and ceftiofur were able to decrease the prevalence of Salmonella. No difference $(\mathrm{P}>0.05)$ was found in both treatments on the prevalence of $E$. coli and aerobic plate count. 
Table 1. The prevalence of Salmonella, Escherichia coli and aerobic plate count in live broilers $(\mathrm{n}=600)$ from the control and antibiotic treatments from weeks 1 through 6

\begin{tabular}{ccccccc}
\hline & \multicolumn{3}{c}{ Control } & \multicolumn{3}{c}{$0.05 \%$ sulfadimethoxine } \\
\cline { 2 - 7 } Week & No. (\%) & No. (\%) & No. (\%) & No. (\%) & No. (\%) & No. (\%) \\
Salmonella & E.coli & APC & Salmonella & E. coli & APC \\
\hline 1 & 96.7 & 96.7 & 100 & 100 & 100 & 100 \\
2 & 100 & 100 & 100 & 100 & 100 & 100 \\
3 & 86.7 & 80.0 & 100 & 83.3 & 76.7 & 93.3 \\
4 & 96.7 & 96.7 & 100 & 93.3 & 93.3 & 100 \\
5 & 100 & 100 & 100 & 96.7 & 100 & 100 \\
6 & 100 & 100 & 100 & 90.0 & 100 & 100 \\
\hline
\end{tabular}

\section{Conclusions}

This study revealed that poultry is a source of Salmonella and E. coli in small-scale poultry farming. This may contribute to cross-contamination of meat carcasses after slaughter and retail products. Therefore, the use of sulfadimethoxine as an antibiotic can reduce the enumeration of Salmonella, Escherichia coli and aerobic plate count in small-scale broiler operations.

\section{Acknowledgements}

This work was partly funded by the McNeese State University Juliet Hardtner Women in Science and Technology Endowed Professorship. We thank Dr. Ray Neyland and Mrs. Jan Prudhomme who provided assistance for this study.

\section{References}

Aarestrup, F. M. (2000). Occurrence, selection and spread of resistance to antimicrobial agents used for growth promotion for food animals in Denmark. APMIS101, 1-48. https://doi.org/10.1111/j.1600-0463.2000.tb05380.x

Aarestrup, F. M. (2015). The livestock reservoir for antimicrobial resistance: a personal view on changing patterns of risks, effects of interventions and the way forward. Philosophical Transactions of the Royal Society B: Biological, 370, 1-13. https://doi.org/10.1098/rstb.2014.0085

Alexandra, J. S. (2009). Campylobacter colonization of the turkey intestine in the context of microbial community development. Applied and Environmental Microbiology, 75(11), 3564-3571. https://doi.org/10.1098/rstb.2014.0085

Al-Ghamdi, M. S., El-Morsy, F., Al-Mustafa, Z. H., Al-Ramadhan, M., \& Hanifm, M. (1999). Antibiotic resistance of Escherichia coli isolated from poultry workers, patients and chicken in the eastern province of Saudi Arabia. Tropical Medicine \& International Health, 4, 278-283. https://doi.org/10.1046/j.1365-3156.1999.00392.x

Antunes, P., Mourão, J., Campos, J., \& Peixe, L. (2016). Salmonellosis: the role of poultry meat. Clinical Microbiology and Infection, 22, 110-121. https://doi.org/10.1016/j.cmi.2015.12.004

Association of official analytical chemists (AOAC). (2000). Official Methods of Analysis. 17th ed. Gaithersburg, MD, USA.

Authority, E. F. S. (2016). The European union summary report on trends and sources of zoonoses, zoonotic agents and food-borne outbreaks in 2015. European Food Safety Authority Journal, 14, 4634. https://doi.org/10.2903/j.efsa.2016.4634

Barrow, P. A., Jones, M. A., Smith, A. L., \& Wigley, P. (2012). The long view: Salmonella- the last forty years. Avian Pathology, 41, 413-20. https://doi.org/10.1080/03079457.2012.718071

content in poultry meat in local Iraqi markets. Journal of Microbiology Research, 3(6), 205-207. https://doi.org/10.5923/j.microbiology.20130306.02

Cosby, D. E., Cox, N. A, Harrison, M. A., Wilson, J. L., Buhr, R. J., \& Fedorka-Cray, P. J. (2015). Salmonella and antimicrobial resistance in broilers: a review. Journal of Applied Poultry Research, 24, 408-26. https://doi.org/10.3382/japr/pfv038

Crump, J. A., Sjolund, K. M., Gordon, M. A., \& Parry, C. M. (2015). Epidemiology, clinical presentation, 
laboratory diagnosis, antimicrobial resistance, and antimicrobial management of invasive Salmonella infections. Clinical Microbiology Reviews, 28, 901-37. https://doi.org/10.1128/CMR.00002-15

Davami, A., Peterson, R. A., Jones, W. T., \& Ilardi, R. L. (1987). Compatibility of sulfadimethoxine and ormetoprim with lasalocid and monensin on performance of male broiler chickens. Poultry Science, 66(2), 373-375. https://doi.org/10.3382/ps.0660373

Delaplane, J. P. (1945). Sulfaquinoxaline in preventing upper respiratory infections of chickens inoculated with infective field material containing Pasteurella avicida. American Journal of Veterinary Research, 6, 207-208.

DeRosa, M., Ficken, M. D., \& Barnes, H. J. (1992). Acute airsacculitis in untreated and cyclophosphamide-pretreated broiler chickens inoculated with Escherichia coli or Escherichia coli cell free culture filtrate. Veterinary Pathology, 29, 68-78. https://doi.org/10.1177/030098589202900109

Food and Drug Administration (FDA). (2013). NADA 200-031 Sulfadimethoxine antibacterial soluble powder.

Grumbles, L. C., \& Delaplane, J. P. (1948). Relative activity of sulfamethazine and sulfaquinoxaline against coccidia of chickens under field conditions. Poultry Science, 27, 411-419. https://doi.org/10.3382/ps.0270411

Haleem, A. M., Al-Bakri, S. A., \& Al-Hiyaly, S. A. K. (2013). Determination of microbial

Hanson, R., Kaneene, J. B., Padungtod, P., Hirokawa, K., \& Zeno, C. (2002). Prevalence of Salmonella and E. coli, and their resistance to antimicrobial agents, in farming communities in northern Thailand, Southeast Asian Journal of Tropical Medicine, 33(Suppl. 3), 120-126.

Höll, L., Behr, J., \& Vogel, R. F. (2016). Identification and growth dynamics of meat spoilage microorganisms in modified atmosphere packaged poultry meat by MALDI-TOF MS. Food Microbiololy, 60, 84-91. https://doi.org/10.1016/j.fm.2016.07.003

Huff, W. E., Huff, G. R., Rath, N. C., Balog, J. M., \& Donoghue, A. M. (2002). Prevention of Escherichia coli infection in broiler chickens with a bacteriophage aerosol spray. Poultry Science, 81, 1486-1491. https://doi.org/10.1093/ps/81.10.1486

Klare, I., Badstübner, D., Konstabel, C., Böhme, G., Claus, H., \& Witte, W. (1999). Decreased incidence of vanA-type vancomycin-resistant enterocci isolated from poultry meat and from fecal samples of humans in the community after discontinuation of avoparcin usage in animal husbandry. Microbial Drug Resistance, 5, 45-52. https://doi.org/10.1089/mdr.1999.5.45

Lee, M. K., Runyon, M., Herrman, J. T., Phillips, R., \& Hsieh, J. (2015). Review of Salmonella detection and identification methods: Aspects of rapid emergency response and food safety. Food Control, 47, $264-76$. https://doi.org/10.1016/j.foodcont.2014.07.011

Lutful, K. S. M. (2010). Avian colibacillosis and salmonellosis: a closer look at epidemiology, pathogenesis, diagnosis, control and public health concerns. International journal of environmental research and public health, 7, 89-114. https://doi.org/10.3390/ijerph7010089

Mazengia, E., Samadpour, M., Hill, H. W., Greeson, K., Tenney, K., Liao, G., ... Meschke, J. S. (2014). Prevalence, concentrations, and antibiotic sensitivities of Salmonella serovars in poultry from retail establishments in Seattle, Washington. Journal of Food Protection, 77, 885-93. https://doi.org/10.4315/0362-028X.JFP-13-394

Nolan, L. K. (2019). Overview of Colibacillosis in poultry. University of Georgia. Retrieved from https://www.merckvetmanual.com/poultry/colibacillosis/overview-of-colibacillosis-in-poultry

Orton, C. T., \& Hambly, L. R. (1971). Efficacy studies on potentiated sulfadimethoxine as a chicken coccidiostat. Poultry Science, 50(5), 1341-1346. https://doi.org/10.3382/ps.0501341

Page, S. W., \& Gautier, P. (2012). Use of antimicrobial agents in livestock. Revue Scientifique et Technique, 31, 145-88. https://doi.org/10.20506/rst.31.1.2106

Piercy, D. W. T., \& West, B. (1976). Experimental Escherichia coli infections in broiler chickens: Course of the disease induced by inoculation via the air sac route. Journal of Comparative Pathology, 86, 203-210. https://doi.org/10.1016/0021-9975(76)90044-X

Rouger, A., Tresse, O. I. D., \& Zagorec, M. (2017). Review bacterial contaminants of poultry meat: sources, species, and dynamics. Microorganisms, 5, 50. https://doi.org/10.3390/microorganisms5030050 
Seiffert, S. N., Hilty, M., Perreten, V., \& Endimiani, A. (2013). Extended-spectrum cephalosporin-resistant gram-negative organisms in livestock: an emerging problem for human health?. Drug Resistance Updates, $16,22-45$.

Simonsen, G. S., Haaheim, H., Dahl, K. H., Kruse, H., Løvseth, A., Olsvik, Ø., \& Sundsfjord, A. (1998). Transmission of vanAType vancomycin-resistant enterococci and vanA resistance elements between chicken and humans at avoparcin-exposed farms. Microbial Drug Resistance, 4, 313-318. https://doi.org/10.1089/mdr.1998.4.313

Statistical Analysis Software (SAS). (2003). SAS User's Guide Version 9.1.3. Cary, NC.: SAS Institute Inc.

Tangkham, W., Janes, M., \& LeMieux, F. (2016a). The effects of sulfadimethoxine administered to control Campylobacter jejuni in small-scale broiler operations. Poultry, Fisheries and Wildlife Sciences, 4, 166. https://doi.org/10.4172/2375-446X.1000166

Tangkham, W., Janes, M., \& LeMieux, F. (2016b). Prevalence and distribution of Campylobacter jejuni in small-scale indoor and outdoor poultry production. Journal of Food Protection, 79(1), 75-81. https://doi.org/10.4315/0362-028X.JFP-15-331

Tessi, M. A., Salsi, M. S., Caffer, M. I., \& Moguilevsky, M. A. (1997). Drug resistance of Enterobacteriaceae isolated from chicken carcasses. Journal of Food Protection, 60, 1001-1005. https://doi.org/10.4315/0362-028X-60.8.1001

Van Den Bogaard, A. E., London, N., Driessen, C., \& Stobberingh, E. E. (2001). Antibiotic resistance of faecal Escherichia coli in poultry, poultry farmers, and poultry slaughterers. The Journal of Antimicrobial Chemotherapy, 47, 763-771. https://doi.org/10.1093/jac/47.6.763

Vree, T. B., \& Hekster, Y. A. (1987). Clinical pharmacokinetics of sulfonamides and their metabolites. $H$. Schonfeld, ed. 37, 1-9. https://doi.org/10.1159/isbn.978-3-318-03212-3

Waletzky, E., \& Hughes, C. O. (1946). The relative activity of sulfonamides and other compounds in avian coccidiosis. American Journal of Veterinary Research, 7, 365-373.

Wang, J., MacNeil, D. J., \& Kay, F. J. (2012). Chemical analysis of antibiotic residues in food (1stedn). John Wiley and Sons Press, 242. https://doi.org/10.1002/9781118067208

Whitehill, A. R., Oleson, J. J., \& Hutchings, B. L. (1950). Stimulatory effect of aureomycin on the growth of chicks. Proceedings of the Society for Experimental Biology and Medicine, 74, 11-13. https://doi.org/10.3181/00379727-74-17793

Zhang, Q. Q., Han, Y. Q., Cao, J. X., Xu, X. L., Zhou, G. H., \& Zhang, W. Y. (2012). The spoilage of air-packaged broiler meat during storage at normal and fluctuating storage temperatures. Poultry Science, 91, 208-214. https://doi.org/10.3382/ps.2011-01519

\section{Copyrights}

Copyright for this article is retained by the author(s), with first publication rights granted to the journal.

This is an open-access article distributed under the terms and conditions of the Creative Commons Attribution license (http://creativecommons.org/licenses/by/4.0/). 